\title{
The technological innovation systems framework: Response to six criticisms ${ }^{\text {is }}$
}

\author{
Jochen Markard $^{\mathrm{a}, *}$, Marko Hekkert ${ }^{\mathrm{b}}$, Staffan Jacobsson ${ }^{\mathrm{c}}$ \\ a Swiss Federal Institute of Technology Zurich, Department of Management, Technology and Economics, Group for Sustainability and \\ Technology, Weinbergstrasse 56/58, 8092 Zurich, Switzerland \\ b Utrecht University, Copernicus Institute of Sustainable Development and Innovation, Department of Innovation Studies, \\ Heidelberglaan 2, 3584CS Utrecht, The Netherlands \\ c Chalmers University of Technology, Environmental Systems Analysis, 41296 Gothenburg, Sweden
}

\section{A R T I C L E I N F O}

\section{Article history:}

Received 28 June 2015

Received in revised form 4 July 2015

Accepted 6 July 2015

Available online 22 July 2015

\section{Keywords:}

Technological innovation systems

Technological change

Transitions

Sustainability

Critique

\begin{abstract}
A B S T R A C T
The technological innovation systems framework (TIS) is widely used to study the emergence and growth of new technological fields and industries. At the same time, it has been criticized for a number of issues and innovation scholars have made suggestions of how to improve the framework. In this viewpoint, we respond to six areas of criticism: (1) TIS context, (2) system delineation, (3) spatial aspects, (4) transitions, (5) politics, and (6) policy recommendations. We point to promising conceptual developments of how to address shortcomings and highlight needs for further research. We also discuss the prospects of the TIS approach for the analysis of socio-technical transitions. The TIS framework, in our view, has the potential to outgrow its original scope - explaining the dynamics and performance of a technological field - and to address many of the issues relevant when studying transitions.
\end{abstract}

(c) 2015 Elsevier B.V. All rights reserved.

\section{Introduction}

The technological innovation systems (TIS) approach has gained quite some attention ${ }^{1}$ in recent years for the study of emerging technologies in and beyond the context of sustainability transitions. It focuses on understanding the dynamics of an innovation system centered around a specific technology. In particular, the approach is often used to assess the performance of a TIS, to identify shortcomings and to derive recommendations for the design of policies in support of a specific technology (Alkemade et al., 2011; Jacobsson and Karltorp, 2013; Weber and Rohracher, 2012; Wieczorek and Hekkert, 2012). Indeed, the latter was a central motivation for developing the framework (Carlsson et al., 2010).

Since its inception (Carlsson and Stankiewicz, 1991), the framework has seen several conceptual developments, including a clarification of scoping issues (Carlsson et al., 2002), TIS functions as a central tool for performance assessment (Bergek et al., 2008a; Hekkert et al., 2007; Jacobsson and Bergek, 2006), specifications for selected TIS functions (Dewald and Truffer, 2012;

\footnotetext{
ts The present viewpoint is part and parcel of a debate about the challenges of TIS research in the current issue of EIST. See Truffer (this issue) for an introduction and overview on the different contributions to the debate.

* Corresponding author. Fax: +41 446321045.

E-mail address: jmarkard@ethz.ch (J. Markard).

1 From 2008, when the term was coined, to 2014, the Scopus Database reports more than 80 papers, which refer to "technological innovation systems" either in their title or keywords. Note that this number does not cover the many publications on the origins of the framework under the notion of ‘technological systems' since 1991.
} 
Bergek et al., 2008b), a strategic perspective on system building (Hellsmark and Jacobsson, 2009; Musiolik and Markard, 2011; Musiolik et al., 2012), international ties within TIS (Bento and Fontes, 2015; Binz et al., 2014), and suggestions for the analysis of TIS contexts (Bergek et al., 2015; Markard et al., 2009; Wirth and Markard, 2011). In fact, the TIS framework is constantly evolving and the debate at the International Conference for Sustainability Transitions in 2014 and in this special issue is part of this development.

As the TIS approach became more widely adopted, it was also criticized. In this article, we address and reflect on the critique. We respond to the three viewpoints in this special issue (Bening et al., 2015; Coenen, 2015; Kern, 2015) and to earlier criticisms in the literature on innovation and transition studies.

Altogether, we cover six major critical issues. The first is about the TIS approach being inward-oriented, thus, downplaying the importance of external context structures. This is related to the second issue of how to delineate a TIS. The third point is about geographical issues being not well enough covered. Fourth, it has been questioned whether the TIS framework is actually a useful framework for analyzing transition processes. The fifth criticism is about a marginal role of politics. The sixth and final point relates to normative issues and the type of policy advice that follows from TIS analyses.

For each of these issues, we will briefly summarize the main aspects of the critique, clarify where we agree or disagree and explain why. In particular, we discuss what the TIS framework can embrace and what is beyond its capacity. With this contribution, we want to further improve the TIS approach. We view conceptual development as an important and ongoing process that - hopefully - takes a step forward with this debate but certainly does not end here.

Note that much of the critique is related to the original purpose of the TIS framework, i.e. how it is used (i) to study the dynamics and performance of (novel) technological fields, (ii) to identify shortcomings, and (iii) to make (policy) recommendations for improvement. Some of the critique, however, also relates to new challenges arising from the study of sustainability transitions-a novel field of research occupied with large-scale transformation processes of sectors such as energy, transportation, food or water towards more sustainable production and consumption (Markard et al., 2012). The TIS approach is viewed as one of the key frameworks in this field for mainly two reasons. First, the emergence of novel technologies is a central processes in socio-technical transitions and several new technologies have meanwhile matured to a degree that they very much threaten established technologies, organizations, and institutional structures. Second, a host of recent empirical work using the TIS approach has studied technologies (e.g. renewable energies, alternative vehicle technologies) that are associated with sustainability promises. As a consequence, the TIS framework is increasingly confronted with both issues, transitions (cf. Section 5) and sustainability (cf. Section 7).

\section{How does the TIS deal with context?}

A recurring critique of the TIS approach is about a perceived myopia and lack of attention to context factors. It has been argued, for example, that the framework is "inward oriented and does not pay much attention to the system's environment" (Markard and Truffer, 2008; p.610) or that "...the actual success of innovation is mainly regarded as a consequence of the performance of the innovation system itself." (Smith and Raven, 2012; p.1029). In particular, it was argued that the TIS approach might miss out on the emergence of complementary or competing technologies in its context, as well as on the struggle for dominance with incumbent technologies.

This critique became an anchor point to suggest more explicit context analyses, for example, by differentiating other technological innovation systems, socio-technical regimes and landscape influences in the context of the TIS (Markard and Truffer, 2008; Wirth and Markard, 2011). However, the critique was also used to rule out the applicability of the TIS concept for analyzing transitions (Geels, 2011; Smith and Raven, 2012). We will come back to that in Section 5.

\subsection{Response}

We are sympathetic to conceptual extensions of the TIS framework, which aim at a differentiated analysis of context structures, their dynamics, and interplay with the focal TIS. In fact, together with co-workers, we make further suggestions for a systematic TIS context analysis in a paper that is part of this special issue (Bergek et al., 2015). At the same time, we also have to make clear that the TIS framework has never ignored the context. To explain this, we have to go back to the origins of the approach, arguing that the TIS functions represent an explicit approach to take context factors into account.

The late 1980s and early 1990s saw the emergence of innovation system concepts with different delineations. These included national, regional and sectoral innovation systems. In addition, Carlsson and Stankiewicz (1991) developed a framework focusing on technologies and products, which was the start of work on TIS. Throughout the 1990s, structures of systems with different delineations were explored. These included knowledge fields, e.g. biomaterials (Rickne, 2000), industries, e.g. factory automation (Carlsson and Jacobsson, 1994), and sectors, e.g. biomedical (Carlsson, 2002). In the 1990s, research on TIS shifted from exploring static structures to analyzing the dynamics of systems. It was then argued that, in times of technological discontinuities, transformation processes at various levels, e.g. technological, sectoral, and national, interact. As a consequence, scholars pointed to a variety of context factors that affect TIS development:

“...industrial growth is not only influenced by factors specific to a technological system, but also by those that a range of technological system has in common... thus, our analytical framework... also needs to consider elements drawn from other system approaches... These factors may be fully technology-specific, but may also influence several 
technological systems simultaneously. Hence, they can be derived from a system perspective using different units of analyses: technology, industry and nation." (Johnson and Jacobsson, 2001; p.91-93).

It was also acknowledged that context structures, including existing technologies and institutions, may obstruct the development of new technologies:

"...in the competition between an emerging new technological system and an incumbent one, the latter is supported by a whole set of institutions, for instance in the form of legislation favoring the incumbent technology." (Jacobsson and Johnson, 2000; p.633).

There was, indeed, an early appreciation of a wide variety of contextual factors leading to problems for TIS to emerge-an appreciation that drew on a rich and abundant literature on e.g. local search processes (Dosi et al., 1988), path dependency and lock-in (Arthur, 1987; Cowan, 1990; David, 1985).

The need to include structural elements in the context of a focal TIS also contributed to the development of the functions approach in the TIS framework in that system functions are viewed as intermediate variables between system performance and structural elements at various levels, including the TIS and the context (Johnson and Jacobsson, 2001).

"By conducting a functional analysis, an analyst may... be guided to the specific structural causes of functional weaknesses that are in the way of an improved performance of the system. Structural system weaknesses are not only found on the level of a specific TIS, but can also reside at sectoral and national system levels." (Jacobsson and Bergek, 2011; p.46).

Hence, in a functional analysis an analyst takes into account both endogenous and exogenous structural elements that influence the dynamics of the system.

However, we agree that more can be done in terms of context analysis and the impact of a focal TIS on the context. If we regarded the context just as a background for TIS development, made up of barriers and driving factors, we would miss, for example, context dynamics that unfold both independently and as a consequence of TIS development. We would also miss institutional coherences in context structures, which tells us much about the resistance proponents of the new technology will face in their quest for broader institutional change. A further reason for a more differentiated context analysis is to understand how variation in context structures affects variations in TIS development, including different applications, designs, or pathways of a novel technology. This is why we suggest a scheme for TIS context analysis in Bergek et al. (2015) and very much welcome further conceptual advancements towards this end.

\section{How to delineate a TIS?}

Related to the 'context critique' is the question of how to delineate a TIS and how to identify relevant structures in the TIS context. Coenen (2015) argues that TIS scholars should not only regard the distinction of TIS and context as an analytical choice but should also pursue a "situationalist" approach for boundary setting that empirically, and on a case-by-case basis, traces TIS structures and influential context systems, e.g. by following actors and their networks. If TIS boundaries are defined ad hoc and based on simple templates, so the underlying concern, the analyst may miss out on important relationships or interactions.

\subsection{Response}

The issue of where and how to draw TIS boundaries is very central to TIS studies. We agree that TIS delineation has to be done carefully, taking the particularities of each individual case into account. The same applies to the identification of relevant context structures. We often see papers, in which authors just write very briefly about TIS boundaries without explaining their choice or discussing the implications of this choice. This is not at all helpful for the development of TIS research. Below we share our thoughts of how to improve research practice.

First, TIS delineation involves several dimensions. These include the breadth of the technological field (narrow or broad range of technology variants or applications), vertical scope (one or several parts of a value chain), spatial focus (local, regional, national, global), or whether to analyze a product or knowledge field (Bergek et al., 2008a). Also the temporal focus needs to be specified (e.g. snapshot type of analysis vs. analysis of different stages of development).

Second, TIS delineation is about making analytical choices, guided by the research question and the purpose of the study. There is no right or wrong whether to analyze, for example, electric vehicles, the engines or batteries they need, charging stations or electric mobility more broadly, in a specific city or country or internationally. However, behind these choices there might be interests of R\&D funding agencies or industry actors-in general or even in the role of the principal of a TIS study (cf. Sections 6 and 7).

Third, technologies, actors and institutional structures in the focus of the analysis are interrelated with technologies, actors, and institutions in the context. ${ }^{2}$ Boundary setting can be viewed as cutting through these ties, with the analyst paying

\footnotetext{
2 Coenen (2015) talks of actor networks in this regard.
} 
more attention to relationships within the focal TIS than to those beyond. So there is an inevitable neglect or downplaying of context structures, and relationships to these. TIS analysts have to be aware of that and ideally make the implications transparent.

Fourth, boundary setting is an iterative process rather than a one-time choice. TIS analysts ideally go back and forth between the analytical level and the empirical insights they accumulate in the course of the analysis, ready to adjust the initial choices as new results come up. The following quote highlights that this is not new. In the light of the current debate, however, it is important to emphasize it again.

“...it is therefore crucial to make a deliberate choice, to re-evaluate this throughout the analysis, to draw conclusions as to how the choice of starting point has affected the picture painted, and to communicate the unit of analysis clearly to the recipients of the analysis..." (Bergek et al., 2008a; p.411).

We, therefore, embrace the suggestion of Coenen (2015) to also identify and adjust TIS boundaries empirically and on a case-by-case basis. Such an approach requires thorough analyses along multiple dimensions. Intensity of interaction of different components, collaboration, and knowledge exchange among actors or institutional 'density' may be first ideas of how to integrate empirical findings into the boundary setting process. TIS scholars are just beginning to collect experiences in this regard (e.g. Binz et al., 2014).

Finally, we want to add that the debate about analytical and empirical boundary setting also touches upon the issue whether to regard the TIS as a purely analytical construct or model or as an object that exists 'out there' and can be identified and described empirically. ${ }^{3}$ In our view, a TIS is neither purely abstract nor objectively identifiable in empirical terms but a combination of both. In that regard it is similar to concepts such as sector, industry, technology, or firm.

\section{How to deal with spatial aspects?}

The critique on the spatial dimension of TIS analysis has emerged in the context of the larger research agenda on the 'geography of transitions' (Coenen and Truffer, 2012; Hansen and Coenen, 2015). It contains two aspects. One argument is that, e.g. when focusing on a TIS in a selected country or region, one might miss out on the foreign or global parts of the TIS that also contribute to TIS performance (Binz et al., 2014; Gosens et al., 2015). This issue is not only important for analytical reasons but also with regard to policy intervention. It questions the often implicit assumption in many studies that each focal TIS should develop all necessary structures-and that policy making should intervene if there are deficits (cf. Section 7). Indirectly, this is also a critique of "methodological nationalism" (Coenen, 2015), i.e. TIS analysts often concentrating on a selected technology in a selected country. This has meanwhile emerged as a rather dominant research design and contributed to the urgency with which scholars argue for a more differentiated spatial analysis.

A second argument is about major differences in institutional contexts for TIS development. ${ }^{4}$ Among others, it is argued that TIS development might differ significantly in industrialized, emerging, and developing economies (Blum et al., 2015; Gosens et al., 2015). But the point about institutional differences is also more fine-grained as the following quote shows:

“...supportive conditions (such as cultural predispositions, professional competencies, specific research, and education facilities). These coherent combinations will in general differ from one location to another and may be the result of each region or nation's history, economic structures, cultural preferences, and so on." (Coenen et al., 2012, p.970).

Variation of context has consequences for the transferability of results but also for the applicability of the framework in research settings different from the ones, in which the framework was originally developed (Blum et al., 2015; Schmidt and Dabur, 2014). Coenen (2015), therefore, asks TIS scholars to analyze how geographical contexts matter and why.

\subsection{Response}

With regard to the first point, we strongly agree that the TIS is not about 'everything in one place'. Since long, the TIS framework has been explicit about the implications of boundary setting - including spatial boundaries - and the global nature of innovation (Bergek et al., 2008a; Carlsson and Stankiewicz, 1991). However, there has been little guidance of how to deal with different TIS structures in different places contributing to the functioning of a TIS. We, therefore, embrace recent studies that analyze how TIS structures in different countries build upon and complement each other (Bento and Fontes, 2015; Quitzow, 2015) or how TIS actors are linked through knowledge networks at a global scale (Binz et al., 2014). Studying the relationships among different sub-systems of a focal TIS that are located in different places is certainly a promising way forward. Such relationships already matter in early phases of TIS development but can be even more prominent in later stages (Quitzow, 2015). Take for example photovoltaics, which has developed into a global industry with different national TIS constituting important parts either downstream (as markets, e.g. Australia), midstream (producers, e.g. China), or upstream (as tech. developers, e.g. Germany).

\footnotetext{
${ }^{3}$ We are grateful to Anna Bergek for highlighting this aspect.

${ }^{4}$ Note that institutional differences are not necessarily coupled to the spatial dimension.
} 
We equally support the development of alternatives to the established dominant research design. A larger diversity of TIS analyses, including those that answer to interactions across different locations, is certainly warranted. At the same time, due to availability of many studies with a similar research design there is potential for a systematic comparison of the findings, e.g. to identify common patterns of development. ${ }^{5}$

The second point about the variety of institutional contexts is also something we very much agree on. This connects, among others, to the literature on varieties of capitalism (Hall and Soskice, 2001), or patterns of democracy (Lijphart, 2012), which has described general differences in economic or political systems. To an extent, TIS analyses capture this variety as they explain different dynamics (between nations or regions) with differences in structure, including institutions. However, the implications of different institutional frame conditions for TIS development deserve more attention and systematic comparative analyses. Studies that have already addressed this issue e.g. how differences in regional professional culture contribute to the emergence of different socio-technical trajectories (Wirth et al., 2013) or how conditions in developing countries affect technology development (Blum et al., 2015; Gosens et al., 2015) may serve as inspiration in this regard.

Institutional context do not just matter in the sense of static backgrounds with different structures. Instead, they may also differ in terms of rigidity and institutional coherence, which may have consequences, among others, for technology legitimacy (Markard et al., 2014). Moreover, institutional contexts may also unfold dynamics of their own, which might again affect the focal technology (cf. Section 2). TIS scholars are only beginning to study these dynamic interactions and we, therefore, agree with Coenen and others that further empirical research and theory development will be needed here.

\section{Is the TIS framework useful for studying transitions?}

In recent years, the TIS framework has been prominently applied for the analysis of emerging technologies in sectors such as energy, transportation, or water. As these novel technologies diffuse and mature, they compete and may eventually help overthrow established technologies, thus, contributing to socio-technical change and transitions more broadly. The TIS approach is, therefore, viewed as a key framework in transition studies (Markard et al., 2012), although it was not designed for this in the first place (Carlsson et al., 2010). So it is a central question whether and how the TIS can be used for understanding socio-technical transitions. Some scholars have denied its applicability right away (Geels, 2011), while others have expressed doubts (Kern, 2015; Markard and Truffer, 2008; Smith and Raven, 2012).

The critique encompasses three aspects. One argument is that the TIS neither accounts for nor explains the rigidities and structural inertia of incumbent socio-technical systems (Geels, 2011; Kern, 2015). This is closely related to the point that the framework has not dealt with the decline of established socio-technical systems and processes of creative destruction (Kern, 2015).

Second, the TIS approach has been criticized for not conceptualizing dynamic interaction between the focal TIS and other socio-technical systems-be they emerging or mature (Markard and Truffer, 2008; Smith and Raven, 2012; Wirth and Markard, 2011). Interaction of multiple technologies is a general issue for TIS studies (cf. Section 2) but also central for socio-technical transitions, which involve a broad range of complementary and competing technologies.

Third, Kern (2015) argues that the TIS cannot be a suitable framework for studying transitions because it "lacks a clear theoretical foundation". Among others, Kern (2015) misses a theoretical explanation of what drives change and what role actors play in this.

\subsection{Response}

Currently, the TIS approach cannot cover all aspects of socio-technical transitions. It does not address the decline of (incumbent) socio-technical systems, nor has it paid much attention to interaction of multiple technologies. This is why, we agree with much of the critique of Kern and others. At the same time, we believe that the TIS approach has the potential to also explain other key processes in socio-technical transitions and that it will be a worthwhile endeavor to further develop the framework in this direction.

What makes us confident - and here we disagree with Kern (3rd aspect) - are the general explanatory value and theoretical foundations of the TIS framework. In general, interdependence and emergence are central concepts when working with systems approaches. It is assumed that the components of a system are closely connected and mutually influence each other (interdependence). This interaction creates patterns and structures (emergence), which again guide interaction and re-produce themselves. Interaction may thus generate positive feedback, also referred to as cumulative causation, so that systems grow and develop momentum. As social systems, innovation systems change autonomously from within, and as a result of external influences, including shocks.

In the case of the TIS, the central elements are different kinds of actors (firms, universities, intermediaries, authorities) that are connected through networks and create new knowledge, products, and technologies under a specific institutional structure (Carlsson and Stankiewicz, 1991). From a static, comparative perspective, ${ }^{6}$ this structure is largely regarded as stable and innovation system scholars are primarily interested to explain differences in performance. From an emerging

\footnotetext{
${ }^{5}$ We thank Anna Bergek for this comment.

${ }^{6}$ Typical for national and sectoral innovation systems and technological systems, the predecessor of the TIS concept.
} 
technologies perspective, scholars are interested in how systems build up structure and expand (Musiolik and Markard, 2011; Suurs and Hekkert, 2009). With this theoretical core, TIS scholars explain (i) essential differences between systems (due to different structures), (ii) creation of variety and non-linearities (due to systemic interaction and cumulative causation) as well as (iii) rigidity and path-dependency (due to structuration).

Another central tenet of the TIS framework is that the performance of the system can be explained by a set of key processes (called functions). While structures may vary across TIS, functions are assumed to be sufficiently generic to apply to a broad range of TIS (Bergek et al., 2008a). Functions are the basis for TIS evaluation, identification of system weaknesses (or blocking mechanisms) and suggestions for how to remove these barriers (Bergek and Jacobsson, 2003; Hekkert et al., 2007). Moreover, since each of the functions are processes that involve external structural elements, system functions may also help us explain the impact of a focal TIS on its context. Take, for instance, 'legitimation' or 'resource mobilisation'. Legitimation is the process by which actors outside of the TIS alter what they see as acceptable or even desirable, e.g. growing political support in Sweden for offshore wind power from regional policy makers. Resource mobilization is the process by which actors in the TIS mobilize e.g. human and financial capital, which is brought into the TIS from the outside.

Against this background, we do not agree that the framework lacks theoretical foundations or explanatory value. We do agree, though, that explanation has so far been limited to either static situations or emerging TIS, thus, missing out on technology decline and larger sector transformation. At the same time we are confident that the core concepts hold and can explain these processes as well. It might well be though that different processes (functions) will be at work for technology decline, compared to technology emergence (Kivimaa and Kern, 2015). The identification and incorporation of new functions would mean another step in the development of an already multi-disciplinary framework.

With regard to the rigidity issue, the TIS framework already has the theoretical apparatus to deal with structures heavily constraining the strategic moves of actors. As emphasized in Section 2, early TIS literature addressed the issue of inertia and lock-in, e.g.:

"Firms, institutions, and networks become 'locked in' to 'old' technologies. Thus, the cumulativeness and path dependency of innovation lead to risks of lock-in into technological, institutional, and networking cul-de-sacs." (Carlsson and Jacobsson, 1997; p.303).

However, rigidity has not been much of an issue in contemporary TIS studies and certainly deserves further theoretical elaboration within the TIS framework.

Finally, with regard to the interaction of multiple technologies, we also agree that further conceptual development is needed. Sandén and Hillman (2011) made an important step in this direction but did not discuss what technology interaction means for the TIS approach. Wirth and Markard (2011) studied the competition of 1st and 2nd generation technologies on the basis of the TIS framework, but did not dig deeper into the actual processes at work. The proposal of Markard and Truffer (2008) to combine the TIS framework with the concept of socio-technical regimes can be another alternative in this regard but again, processes of interaction and how they affect the structures of both emerging and mature TIS will have to be analyzed and conceptualized in more detail.

\section{How can politics be better incorporated into TIS research?}

The emergence of new technologies and the transformation of socio-technical systems deeply affect the positions and strategic interests of incumbent actors and newcomers. As a consequence, conflicts and struggles over the 'right course of action' and who gets what are central elements in innovation and transition processes (Grin, 2010). Such conflicts unfold, among others, over the legitimacy of novel technologies, about whether and how to support a technology by public policy (see also Section 7) or whether to phase out an established technology. Also 'lower level issues' such as who has access to scarce resources, who can attain a leading position in a market, or which design will become a common standard are heavily contested. Below we apply a broad understanding of politics that covers all these processes and struggles, not just the ones related to the realm of policy making.

Existing frameworks in transition studies such as the multi-level perspective, have been criticized for not paying sufficient attention to agency and the 'politics of transitions' (Lawhon and Murphy, 2012; Shove and Walker, 2007; Smith et al., 2010). Kern (2015) argues that this critique also applies to the TIS framework. While acknowledging that the framework incorporates political aspects through the 'legitimation' function, he maintains that politics is much more pervasive and influences other functions too, like 'market formation'. His critique goes even further: assessing the performance through TIS functions - so he argues - backgrounds who is actually driving (or hindering) TIS processes and how. Kern (2015) also argues that “...the relationships between different functions and what results their interplay can produce is under-theorized..." which is why he calls, among others, for an explicit analysis of actors and actor strategies (to uncover the underlying processes).

\subsection{Response}

We agree that the political dimension is of great importance and deserves more attention than is often given to it. We also agree that the concepts for dealing with struggles over institutional change are under-developed in the TIS framework. However, we have to emphasize that politics were acknowledged early on in the development of the TIS framework. Jacobsson and Bergek (2004), for example, point to the contested nature of institutional change and to the importance of technology- 
specific advocacy coalitions, or political networks, with the objective of influencing institutional structures. Moreover, TIS scholars have regularly reported on acts of politics, e.g. lobbying by actors joining forces in emerging TIS or by incumbents opposing new technologies (Jacobsson and Johnson, 2000; Jacobsson and Lauber, 2006; Negro and Hekkert, 2008; Musiolik et al., 2012).

The initial emphasis on the impact of politics on 'legitimation' is arguably justified since it is difficult to conceive of e.g. regulation that supports 'market formation' for emerging technologies, which lack legitimacy. Beyond a direct effect on that function, the institutional set-up has an indirect impact on other functions, e.g. 'influence on the direction of search', 'resource mobilisation', and 'entrepreneurial experimentation' in that the formation of markets may influence the search for business opportunities among firms which may allocate resources to a new field and experiment with new product development and business strategies. Additionally, politics may have a direct impact on other functions than 'market formation'. For instance, vested interests influencing the funding pattern of academic R\&D may impact on the content of 'knowledge development and diffusion'.

While further work on the pervasive impact of politics on functional dynamics would be appreciated, it is, thus, a misunderstanding that politics is of marginal importance in TIS-analyses and seen to influence 'legitimation' only. Instead, it is common to divide the structural element "networks" into "learning networks" and "political networks", highlighting the importance of politics (Jacobsson and Bergek, 2011; Jacobsson and Karltorp, 2013). TIS dynamics include political dynamics in the form of e.g. stronger political networks as more firms enter a TIS and participate in the political process (Jacobsson and Lauber, 2006). Yet, Kern (2015) has a point here that agency may not be foregrounded enough to provide an adequate explanation to (lack of) dynamics, a point also raised by Smith and Raven (2012). From that does not follow that 'motors of innovation' is not useful, but rather that agency, including politics, need to be systematically incorporated into the analysis in order to more fully explain dynamics.

While politics is not of marginal importance, Kern (2015) is right that the main focus is not on the political narratives of incumbents (with associated actors) and advocates of challenging TISs. Instead, these are one factor out of many that are addressed in a systems approach. The TIS perspective is primarily a meso-level perspective and, therefore, by definition it cannot bring to the fore all micro mechanisms. However, as TIS has a strong focus on actors (which is a core concept, just as political networks), it is rather straightforward to include strategies, positions, networks, coalitions etc. in the analysis. The insights gained from such studies can then be incorporated into comprehensive TIS studies. Indeed, we would encourage a greater attention to such micro level analyses, which can enrich our understanding at the meso-level.

To conclude, we agree with Kern (2015) that more emphasis may be placed on politics in analyses of TIS dynamics. Indeed, his suggestions to focus more on the national institutional framework (part of a NIS approach) and on cross-country comparisons of the political economy of transitions are useful as is his suggestion to systematically map the political agency of various actors.

\section{What are the limits for policy recommendation?}

As the TIS framework is frequently used for making policy recommendations, it has also received critique in this regard. Below we discuss two aspects, the desirability of a particular technology and the specificity of policy advice.

Bening et al. (2015) point to the normative aspects associated with many TIS studies in that they provide policy recommendations in support of a specific technology (possibly at the expense of other technologies). TIS scholars, so the argument goes, have to justify why a selected technology should be supported by policy. This critique is frequent, as the TIS framework is regularly applied to 'clean' technologies, which are - often implicitly - assumed to be socially desirable.

Another issue is the specificity of policy recommendations. Bening et al. (2015) argue that many TIS studies make rather generic and broad policy recommendations. Instead, the authors call for workable policy recommendations. They argue that from their experience, policy makers prefer specific and substantiated recommendations for integration into the policy making process.

\subsection{Response}

We share the impression that some TIS scholars seem to be advocates of the technologies they are studying and may not keep sufficient distance to the object they study. However, this has no connection to the TIS framework. The framework can be used for any technology, regardless of whether it is viewed as desirable or not (and by whom), and it does not entail any kind of (explicit or implicit) technology assessment. In fact, we may even go a step further claiming that no scientific framework can justify technology choices. Instead, such decisions are essentially political: science can support decisions (e.g. through life cycle assessments) but cannot be a substitute for them (Stirling, 2010).

When the Swedish Board for Technical Development (STU) initiated the work that led to early versions of the TIS framework, the objective was to develop an understanding of technical change that could meet the operational needs of the agency in designing policies geared towards specific, already prioritized technologies, or industries. Hence, the technology choice was not an area of concern for the analyst who studied strengths and weaknesses of an a priori selected technological field 
and suggested inroads for policy making to support the selected technology. ${ }^{7}$ Whether such support is desirable for certain stakeholders or society more broadly is a different issue. Against this background, we disagree with Bening et al. (2015) that TIS studies should necessarily be accompanied with a justification why a particular technology deserves policy support.

In the viewpoint by Bening et al. (2015), we sense an implicit desire for TIS studies to have more impact on policy making and we are generally sympathetic to this. However, we bring forward two points for further consideration.

The first is about the politics involved in the development of new technologies and transitions more broadly (see Section 6) and a potentially naïve understanding of the role of academic research in policy consulting. Far-reaching changes in established socio-technical systems involve a broad range of interests, which permeate and influence the decisions of government, parliament, and administration. Policy makers are neither independent (of e.g. economic interests) nor can they be expected to pay particular attention to the results of academic research. The ambition to improve the policy impact of TIS studies has to be seen in the light of these constraints.

Second, we question the claim that policy makers prefer specific recommendations. The experience of Swedish academics in the early phase of TIS development was the exact opposite in that it was made clear that policy makers did not want to have the usual 'policy recommendations' section in academic papers but desired new frameworks to guide them in their thinking about policy. This was also the view of the Swedish Energy Agency when they recently contracted a group of academics to undertake TIS work in five technological fields, where the task was to identify the systemic problems but not to supply specific policy recommendations (Swedish Energy Agency, 2014). Also the experiences of Dutch academics in informing policy makers is that policy makers are in great need of being informed about the systemic problems in emerging innovation systems that require policy attention. However, they see it as their task to design innovation policies to deal with these systemic problems and a detailed policy action plan is not what they demand from academics. It is exactly the argument of complex political environments made by Bening et al. (2015) that policy makers use when they ask for insights and not for recipes.

Having said this, we acknowledge that academics have an option to follow the advice of Bening et al. (2015). With the wider use of TIS in a time of dire warnings for the future of human kind (IEA, 2013; World Bank, 2014) and ongoing transformations in sectors such as energy or transportation, normative issues associated with technology development become increasingly relevant-especially in those cases, where the focal technology is heavily contested (Lauber and Jacobsson, 2015). Academics may, therefore, take the position that the usefulness of their research may be enhanced with an engagement in the future of specific technologies, e.g. by adding analyses of environmental or economic impacts to the TIS study. Yet, a more active engagement needs to be complemented with a clear normative statement where the academic argues his/her stance.

A complementary option would be to take the step from a TIS analysis to developing an action plan for a specific technology, in which concrete and specific policy recommendations are made which deal with the pinpointed system weaknesses. The academic must, though, be aware that(s) he will then take the step into a political minefield, in which not only opposing business interests are active, but also other academics, politicians, civil servants, journalists, and others participating in the political debate. The academic needs, therefore, to acknowledge political realities and processes as well as take into account interaction with existing policies.

\section{Conclusions and outlook}

The TIS approach is an often-applied framework to study the emergence and growth of new technological fields and their performance. The approach has been used for a broad range of studies including but not limited to novel technologies that carry the promise of improving sustainability. Over the past 15 years the framework has seen major conceptual development and this process is still ongoing. We believe that constructive criticism as expressed in this special issue and by other researchers before is extremely important for further improving the TIS approach.

Apparently, not only the framework but also the interests and needs of researchers are changing. There are at least three major trends we observe at the moment: (i) an increasing interest in 'clean' technologies and sustainability issues, (ii) a maturation, global expansion and growing socio-economic impact of former 'emerging' technologies such as solar or wind, and (iii) a rising interest in the study of sectoral transformation and socio-technical transitions. Independently but even more so in combination, these issues translate into new demands the TIS framework is confronted with.

Sustainability issues, for example, imply that public policies may play a key role in the development of technological fields, which is why the underlying processes of technology legitimation, policy making, and regulatory change deserve major attention (Bergek et al., 2008b; Jacobsson and Lauber, 2006; Kern, 2009; Markard et al., 2015). Maturation and expansion of TIS, raises issues on international knowledge flows (Binz et al., 2014), 'global' value chains (Dewald and Fromhold-Eisebith, 2015) and interaction between up- and down-stream parts of TIS in different places (Bento and Fontes, 2015). Maturation of TIS also relates to a growing impact on existing institutional structures, organizations, and technologies together with an increasing demand for material, financial, and human resources (Jacobsson and Karltorp, 2012; Markard et al., 2014; Wirth and Markard, 2011). Sectoral change and transitions, finally, call for concepts to understand the interaction of multiple

\footnotetext{
${ }^{7}$ Note that the TIS framework provides an understanding of technology dynamics, which could also be used to derive policies to hinder the development of the focal technology.
} 
technologies (Sandén and Hillman, 2011), reactions of incumbents (Smink et al., 2015), political strategies (Wesseling et al., 2014) and decline of socio-technical systems (Turnheim and Geels, 2012).

In our view, the TIS framework has the potential to address many of these issues. Its emphasis on the key role of different kinds of actors, networks, and institutional structures together with its systemic approach, makes it possible to provide generalizable insights into a broad variety of change processes and also facilitates the connection to related strands of literature. TIS scholars have already begun to make these connections.

Currently, at least four major areas of development can be identified. One is about the 'geography of innovation'. It has received much attention in recent years (e.g. Truffer and Coenen, 2012; Hansen and Coenen, 2015) and includes topics such as the spatial differentiation of TIS, international value chains, knowledge flows and collaboration, location of 'innovation hot spots' and the role of cities for emerging technologies, or regional variation of TIS and contexts. This area has clear overlaps with, and is inspired by, the broader field of economic geography. A second area of development is the interaction between a TIS and existing institutional structures in the TIS context (e.g. Bergek et al., 2015; Wirth and Markard, 2011; Wirth et al., 2013). Here, researchers have to study issues such as institutional embedding and shaping of TIS, adaptation of context structures, institutional coherence in different contexts, variation in TIS development pathways etc. Towards this end, concepts and insights from institutional theory can be mobilized, among others. Third, TIS scholars have directed attention to the various micro-level processes underlying TIS formation, including network building and formation of coalitions, creation of collective resources, shaping of expectations, or market creation (e.g. Dewald and Truffer, 2011; Kukk et al., 2015; Musiolik and Markard, 2011; Musiolik et al., 2012). This line of research has benefited, among others, from concepts in the strategic management literature. It also links up with actor-centered concepts in the field of policy analysis (e.g. Sabatier, 2007). Fourth, researchers work towards adapting and applying the TIS framework for the study of socio-technical transitions (e.g. Markard and Truffer, 2008; Markard and Hekkert, 2013). This is a rather recent area of conceptual development that has to address issues such as interaction of multiple technological innovation systems, system decline, TIS lifecycle etc. There are obvious overlaps with the literature on sustainability transitions (Markard et al., 2012) and industry lifecycles (Anita et al., 2004). In the light of these different conceptual developments, we expect the TIS framework to maintain and strengthen its position as one of the key frameworks in the field of innovation studies.

\section{Acknowledgements}

We are grateful for the substantial and very constructive comments we received from Anna Bergek and Bernhard Truffer on an earlier version of this article. We also thank Bernhard for organizing the panel at the IST 2014 conference in Utrecht and Floortje Alkemade for managing this special issue.

\section{References}

Alkemade, F., Hekkert, M.P., Negro, S.O., 2011. Transition policy and innovation policy: Friends or foes? Environ. Innovation Soc. Transitions 1, 125-129.

Anita, M.M., Nicholas, A., Joel, A.C.B., 2004. Context, Technology and Strategy: Forging New Perspectives on the Industry Life Cycle, Business Strategy Over the Industry Lifecycle. Emerald Group Publishing Limited, pp. 1-21.

Arthur, W.B., 1987. Competing technologies: An overview. In: Dosi, G., Freeman, C., Nelson, R.R., Silverberg, G., Soete, L. (Eds.), Technical Change and Economic Theory. Columbia University Press, New York, pp. 590-607.

Bening, C.R., Blum, N.U., Schmidt, T.S., 2015. A comment on how to increase the policy relevance of the technological innovation system and its functions approach. Environ. Innovation Soc. Transitions (this issue).

Bento, N., Fontes, M., 2015. Spatial diffusion and the formation of a technological innovation system in the receiving country: The case of wind energy in Portugal. Environ. Innovation Soc. Transitions 15, 158-179.

Bergek, A., Hekkert, M.P., Jacobsson, S., Markard, J., Sanden, B.A., Truffer, B., 2015. Technological innovation systems in contexts: Conceptualizing contextual structures and interaction dynamics. Environ. Innovation Soc. Transitions. (in press).

Bergek, A., Jacobsson, S., 2003. The emergence of a growth industry: A comparative analysis of the German, Dutch and Swedish wind turbine industries. In: Metcalfe, J.S., Cantner, U. (Eds.), Change, Transformation and Development. Physica-Verlag (Springer), Heidelberg, pp. 197-228.

Bergek, A., Jacobsson, S., Carlsson, B., Lindmark, S., Rickne, A., 2008a. Analyzing the functional dynamics of technological innovation systems: A scheme of analysis. Res. Policy 37, 407-429.

Bergek, A., Jacobsson, S., Sanden, B.A., 2008b. 'Legitimation' and 'development of external economies': Two key processes in the formation phase of technological innovation systems. Technol. Anal. Strat. Manage. 20, 575-592.

Binz, C., Truffer, B., Coenen, L., 2014. Why space matters in technological innovation systems-mapping global knowledge dynamics of membrane bioreactor technology. Res. Policy 43, 138-155.

Blum, N.U., Bening, C.R., Schmidt, T.S., 2015. An analysis of remote electric mini-grids in Laos using the technological innovation systems approach. Technol. Forecasting Soc. Change 95, 218-233.

Carlsson, B., 2002. Technological Systems in the Bio Industries: An International Study. Kluwer, Boston.

Carlsson, B., Elg, L., Jacobsson, S., 2010. Reflections on the co-evolution of innovation theory, policy and practice: The emergence of the Swedish agency for innovation systems. In: Smits, R., Kuhlmann, S., Shapira, P. (Eds.), The Theory and Practice of Innovation Policy: An International Research Handbook. Edward Elgar, Cheltenham, pp. 145-166.

Carlsson, B., Jacobsson, S., 1994. Technological systems and economic policy: The diffusion of factory automation in Sweden. Res. Policy 23, 235-248.

Carlsson, B., Jacobsson, S., 1997. In search of useful public policies-key lessons and issues for policy makers. In: Carlsson, B. (Ed.), Technological Systems and Industrial Dynamics. Kluwer Academic Publishers, Dordrecht, pp. 299-315.

Carlsson, B., Jacobsson, S., Holmén, M., Rickne, A., 2002. Innovation systems: Analytical and methodological issues. Res. Policy 31, $233-245$.

Carlsson, B., Stankiewicz, R., 1991. On the nature, function and composition of technological systems. Evol. Econ. 1, 93-118.

Coenen, L., 2015. Engaging with (changing) spatial realities in TIS research. Environ. Innovation Soc. Transitions (this issue).

Coenen, L., Truffer, B., 2012. Places and spaces of sustainability transitions: Geographical contributions to an emerging research and policy field. Eur. Plann. Stud. 20, 367-374.

Cowan, R., 1990. Nuclear power reactors: A study in technological lock-in. J. Econ. Hist. 50, 541-567.

David, P.A., 1985. Clio and the economics of QWERTY. Am. Econ. Rev. 75, 332-337. 
Dewald, U., Fromhold-Eisebith, M., 2015. Trajectories of sustainability transitions in scale-transcending innovation systems: The case of photovoltaics. Environ. Innovation Soc. Transitions (in press)

Dewald, U., Truffer, B., 2011. Market formation in technological innovation systems-diffusion of photovoltaic applications in Germany. Ind. Innovation $18,285-300$.

Dewald, U., Truffer, B., 2012. The local sources of market formation: Explaining regional growth differentials in german photovoltaic markets. Eur. Plann. Stud. 20, 397-420.

Dosi, G., Freeman, C., Nelson, R., Silverberg, G., Soete, L., 1988. Technical Change and Economic Theory. Pinter, London, pp. 646.

Geels, F.W., 2011. The multi-level perspective on sustainability transitions: Responses to seven criticisms. Environ. Innovation Soc. Transitions 1, 24-40.

Gosens, J., Lu, Y., Coenen, L., 2015. The role of transnational dimensions in emerging economy-'Technological Innovation Systems' for clean-tech. J. Clean. Prod. 86, 378-388.

Grin, J., 2010. Understanding transitions from a governance perspective. In: Grin, J., Rotmans, J., Schot, J. (Eds.), Transitions to Sustainable Developmet. Routledge, pp. 223-319.

Hall, P., Soskice, D., 2001. Varieties of Capitalism: The Institutional Foundations of Comparative Advantage. Oxford University Press, Oxford.

Hansen, T., Coenen, L., 2015. The geography of sustainability transitions: Review, synthesis and reflections on an emergent research field. Environ. Innovation Soc. Transitions (in press).

Hekkert, M., Suurs, R.A.A., Negro, S., Kuhlmann, S., Smits, R., 2007. Functions of innovation systems: A new approach for analysing technological change. Technol. Forecasting Soc. Change 74, 413-432.

Hellsmark, H., Jacobsson, S., 2009. Opportunities for and limits to academics as system builders-the case of realizing the potential of gasified biomass in Austria. Energy Policy 37, 5597-5611.

IEA, 2013. Redrawing the Energy-Climate Map, World Energy Outlook Special Report. International Energy Agency, Paris.

Jacobsson, S., Bergek, A., 2004. Transforming the energy sector: The evolution of technological systems in renewable energy technology. Ind. Corp. Change $13,815-849$.

Jacobsson, S., Bergek, A., 2006. A framework for guiding policy-makers intervening in emerging innovation systems in 'catching-up' countries. Eur. J. Dev. Res. 18, 687-707.

Jacobsson, S., Bergek, A., 2011. Innovation system analyses and sustainability transitions: Contributions and suggestions for research. Environ. Innovation Soc. Transitions 1, 41-57.

Jacobsson, S., Johnson, A., 2000. The diffusion of renewable energy technology: An analytical framework and key issues for research. Energy Policy 28, 625-640.

Jacobsson, S., Karltorp, K., 2012. Formation of competences to realize the potential of offshore wind power in the European Union. Energy Policy 44, 374-384.

Jacobsson, S., Karltorp, K., 2013. Mechanisms blocking the dynamics of the European offshore wind energy innovation system-challenges for policy intervention. Energy Policy 63, 1182-1195.

Jacobsson, S., Lauber, V., 2006. The politics and policy of energy system transformation-explaining the German diffusion of renewable energy technology. Energy Policy 34, 256-276.

Johnson, A., Jacobsson, S., 2001. Inducement and blocking mechanisms in the development of a new industry: The case of renewable energy technology in Sweden. In: Coombs, R., Green, K., Richards, A., Walsh, V. (Eds.), Technology and the Market: Demand, Users and Innovation. Edward Elgar, Cheltenham, pp. 89-111.

Kern, F., 2009. The Politics of Governing ‘System Innovations’ Towards Sustainable Electricity Systems, SPRU-Science and Technology Policy Research. University of Sussex, Brighton.

Kern, F., 2015. What future for the technological innovation systems approach in analysing sustainability transitions? Environ. Innovation Soc. Transitions (this issue).

Kivimaa, P., Kern, F., 2015. Creative Destruction or Mere Niche Creation? Innovation Policy Mixes for Sustainability Transitions, SPRU Working Paper Series. Sussex University, Brighton.

Kukk, P., Moors, E.H.M., Hekkert, M.P., 2015. The complexities in system building strategies-the case of personalized cancer medicines in England. Technol. Forecasting Soc. Change 98, 47-59.

Lauber, V., Jacobsson, S., 2015. Lessons from Germany’s Energiewende. In: Fagerberg, J., Laestadius, S., Martin, B. (Eds.), The Triple Challenge: Europe in a New Age. Oxford University Press, Oxford.

Lawhon, M., Murphy, J.T., 2012. Socio-technical regimes and sustainability transitions: Insights from political ecology. Prog. Hum. Geogr. 36, 354-378.

Lijphart, A., 2012. Patterns of Democracy: Government Forms and Performance in Thirty-Six Countries. Yale University Press, New Haven.

Markard, J., Hekkert, M.P., 2013. Technological innovation systems and sectoral change: Towards a TIS based transition framework, IST. In: 4th Conference on Sustainability Transitions, Zurich.

Markard, J., Raven, R., Truffer, B., 2012. Sustainability transitions: An emerging field of research and its prospects. Res. Policy 41, 955-967.

Markard, J., Stadelmann, M., Truffer, B., 2009. Prospective analysis of innovation systems. Identifying technological and organizational development options for biogas in Switzerland. Res. Policy 38, 655-667.

Markard, J., Suter, M., Ingold, K., 2015. Socio-technical transitions and policy change-advocacy coalitions in Swiss energy policy. Environ. Innovation Soc. Transitions (in press).

Markard, J., Truffer, B., 2008. Technological innovation systems and the multi-level perspective: Towards an integrated framework. Res. Policy 37, 596-615.

Markard, J., Wirth, S., Truffer, B., 2014. Institutional dynamics and technology legitimacy-A framework and a case study on biogas technology. In: Paper at the 30th EGOS Colloquium, Rotterdam.

Musiolik, J., Markard, J., 2011. Creating and shaping innovation systems: Formal networks in the innovation system for stationary fuel cells in Germany. Energy Policy 39, 1909-1922.

Musiolik, J., Markard, J., Hekkert, M., 2012. Networks and network resources in technological innovation systems: Towards a conceptual framework for system building. Technol. Forecasting Soc. Change 79, 1032-1048.

Negro, S., Hekkert, M.P., 2008. Explaining the success of emerging technologies by innovation system functioning: The case of biomass digestion in Germany. Technol. Anal. Strat. Manage. 20, 465-482.

Quitzow, R., 2015. Dynamics of a policy-driven market: The co-evolution of technological innovation systems for solar photovoltaics in China and Germany. Environ. Innovation Soc. Transitions (in press).

Rickne, A., 2000. New Technology-Based Firms and Industrial Dynamics Evidence from the Technological System of Biomaterials in Sweden, Ohio and Massachusetts, Department of Industrial Dynamics. Chalmers University of Technology, Göteborg.

Sabatier, P.A., 2007. Theories of the Policy Process. Westview Press, Boulder, CO.

Sandén, B.A., Hillman, K.M., 2011. A framework for analysis of multi-mode interaction among technologies with examples from the history of alternative transport fuels in Sweden. Res. Policy 40, 403-414.

Schmidt, T.S., Dabur, S., 2014. Explaining the diffusion of biogas in India: A new functional approach considering national borders and technology transfer. Environ. Econ. Policy Stud. 16, 171-199.

Shove, E., Walker, G., 2007. CAUTION! transitions ahead: Politics, practice and sustainable transition management. Environ. Plann. A 39, 763-770.

Smink, M.M., Hekkert, M.P., Negro, S.O., 2015. Keeping sustainable innovation on a leash? Exploring incumbents' institutional strategies. Bus. Strat. Environ. 24, 86-101.

Smith, A., Raven, R., 2012. What is protective space? Reconsidering niches in transitions to sustainability. Res. Policy 41, $1025-1036$. 
Smith, A., Voß, J.-P., Grin, J., 2010. Innovation studies and sustainability transitions: The allure of the multi-level perspective and its challenges. Res. Policy $39,435-448$.

Stirling, A., 2010. Keep it complex. Nature 468, 1029-1031.

Suurs, R.A.A., Hekkert, M.P., 2009. Cumulative causation in the formation of a technological innovation system: The case of biofuels in the Netherlands. Technol. Forecasting Soc. Change 76, 1003-1020.

Swedish Energy Agency, 2014. Teknologiska Innovationssystem inom Energiområdet. Energimyndigheten, Eskilstuna.

Truffer, B., Coenen, L., 2012. Environmental innovation and sustainability transitions in regional studies. Reg. Stud. 46, 1-22.

Turnheim, B., Geels, F.W., 2012. Regime destabilisation as the flipside of energy transitions: Lessons from the history of the British coal industry (1913-1997). Energy Policy 50, 35-49.

Weber, K.M., Rohracher, H., 2012. Legitimizing research, technology and innovation policies for transformative change. Res. Policy 41, $1037-1047$.

Wesseling, J.H., Farla, J.C.M., Sperling, D., Hekkert, M.P., 2014. Car manufacturers' changing political strategies on the ZEV mandate. Transp. Res. Part D: Transport Environ. 33, 196-209.

Wieczorek, A.J., Hekkert, M.P., 2012. Systemic instruments for systemic innovation problems: A framework for policy makers and innovation scholars. Sci. Public Policy 39, 74-87.

Wirth, S., Markard, J., 2011. Context matters: How existing sectors and competing technologies affect the prospects of the Swiss Bio-SNG innovation system. Technol. Forecasting Soc. Change 78, 635-649.

Wirth, S., Markard, J., Truffer, B., Rohracher, H., 2013. Informal institutions matter: Professional culture and the development of biogas technology. Environ. Innovation Soc. Transitions 8, 20-41.

World Bank, 2014. Turn Down the Heat. Confronting the New Climate Normal. World Bank, Washington. 